Military Technical College

Kobry Elkobbah, Cairo, Egypt

May 27-29,2008

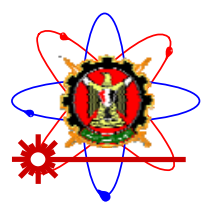

$4^{\text {th }}$ International Conference on Mathematics and Engineering Physics (ICMEP-4)

PH-10

\title{
A TWO-DIMENSIONAL MODEL OF A LASER-METAL INTERACTION
}

\author{
A.El- Desoky* \\ A.Abou El-Soud ** \\ A.El-Nadi $* * *$
}

\begin{abstract}
A two-dimensional cylindrical axisymetrical model for laser-metal interaction is presented in this paper by taking into account the reflection of the laser beam at the surface of the target, the initial and boundary condition, using the continuous and pulsed Gaussian Nd:YAG laser beam. The problem was solved using finite difference method and using Newton Raphson method to calculate the position of the interface, the metals were studied are pure aluminum, magnesium and titanium. The model allows both for heat conduction and melting inside the target. The computational results are temperature fields in both solid and liquid were obtained which provide useful information to practical laser treatment processing.
\end{abstract}

\section{KEY WORDS}

metal, temperature field, Nd:YAG laser, two-dimensions, finite difference.

\section{INTRODUCTION}

From the main characteristic of the laser beam has low divergence is able to deliver high power pre unit area that makes high change in the metal temperature, so the interaction of laser radiation with metals leads to the absorption of electromagnetic energy in a thin film thick, the absorbed energy raises the temperature of the surface layer and the heat propagates into the metal by conduction and then the surface begins to melt and then vaporizes at this initial stage of interaction. The dynamic of laser-metal interaction depends on the laser parameters such as wavelength, beam energy, irradiance and temporal and spatial distribution of intensity and thermal properties of the metal such specific heat, thermal conductivity, thermal diffusivity, and reflectivity [1]. 


\section{MODELING OF THE PROBLEM}

Let a diffusion problem in a finite region $0 \leq R \leq D / 2,0 \leq Z \leq L$ is considered and described by a heat-conduction equation (1) as shown in fig. (1).

The region $0 \leq R \leq D / 2$ is divided into $M$ equal parts of mesh size. The region $0 \leq Z \leq L$ is divided into $N$ equal parts of mesh size.

Where $\Delta r=D / 2 M$ and $\Delta z=L / N$.[2,3]

$T_{a m b}$ is ambient temperature taking equal to $20 C^{\circ}$

$h$ is heat transfer coefficient to ambient taking equal to $0.0134 \mathrm{w} / \mathrm{cm} .{ }^{2} \mathrm{C}^{\circ}$ [4]

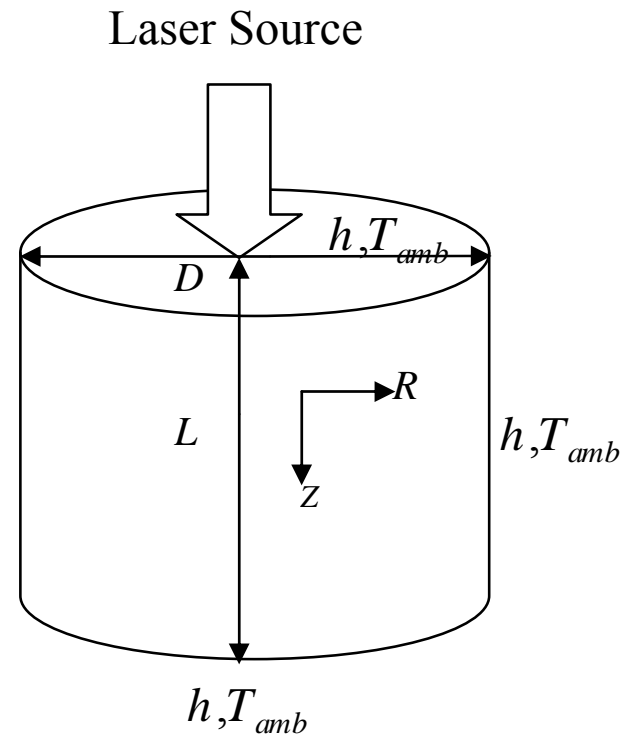

Fig.1. Geometry of two-dimensions model

$$
\frac{\partial^{2} T}{\partial r^{2}}+\frac{1}{r} \frac{\partial T}{\partial r}+\frac{\partial^{2} T}{\partial z^{2}}=\frac{1}{\alpha} \frac{\partial T}{\partial t}
$$

We construct a finite-difference net of rectangular mesh $(\Delta r, \Delta z)$ in the $r, z$ domain over the region. Then the coordinates $(r, z)$ are represented by

$$
r=i \Delta r, \quad z=j \Delta z
$$

Where $i, j=$ positive integers and the time domain is divided into small steps $\Delta \mathrm{t}$. such that

$$
t=n \Delta t
$$

Then the temperature at any location $(r, z)$ at any time $(t)$ is represented by

$$
T(r, z, t)=T(i \Delta r, j \Delta z, n \Delta t)=T_{i, j}^{n}
$$

Various derivatives in equation (1) at a node (i, j), an implicit scheme are used. The finitedifference form using the central difference formula as[5]

$$
\begin{aligned}
& \left.\frac{\partial^{2} T}{\partial r^{2}}\right|_{i, j}=\frac{T_{i-1, j}^{n+1}-2 T_{i, j}^{n+1}+T_{i+1, j}^{n+1}}{(\Delta r)^{2}} \\
& \left.\frac{\partial T}{\partial r}\right|_{i, j}=\frac{T_{i+1, j}^{n+1}-T_{i-1, j}^{n+1}}{2 \Delta r} \\
& \left.\frac{\partial T}{\partial t}\right|_{i, j}=\frac{T_{i, j}^{n+1}-T_{i, j}^{n}}{\Delta t}
\end{aligned}
$$

Introducing equations (2) into equation (1) we obtain 


$$
\begin{aligned}
& \left(1+4 r_{x}\right) T_{i, j}^{n+1}-r_{x}\left(1-\frac{1}{2 i}\right) T_{i-1, j}^{n+1}-r_{x}\left(1+\frac{1}{2 i}\right) T_{i+1, j}^{n+1}- \\
& r_{x} T_{i, j-1}^{n+1}+r_{x} T_{i, j+1}^{n+1}=T_{i, j}^{n}
\end{aligned}
$$

Where $\quad r_{x}=\frac{\alpha \Delta t}{(\Delta r)^{2}}, \quad \alpha=\frac{k}{\rho c}, \quad \Delta r=\Delta z$

$\alpha \ldots \ldots \ldots$....is the thermal diffusivity.

$k \ldots \ldots . .$. is the thermal conductivity.

$\rho \ldots \ldots . . .$. is the metal density.

$c_{p} \ldots \ldots . .$. is the heat capacity.

$$
n=0,1,2,3, \ldots . . \quad, i=1,2, \ldots . M-1 \quad \text { and } j=1,2, \ldots . N-1
$$

Which is the implicit finite-difference form of the heat-conduction equation(1) at the inside node $(i, j)$ for the nonzero values of $r$.

At $r=0, \quad$ due to the temperature at $r=0$ is maximum there, $\frac{\partial T}{\partial r}=0$ thus $\lim _{r \rightarrow 0} \frac{d T}{d r} / r=\frac{0}{0}$ due to this fact the rule of L'Hopital's rule is used. This gives: [6]

$$
\lim _{r \rightarrow 0}\left(\frac{1}{r} \frac{\partial T}{\partial r}\right)=\frac{\partial^{2} T}{\partial r^{2}}
$$

Then the heat-conduction equation (1) at the location $r=0$ takes the form

$$
2 \frac{\partial^{2} T}{\partial r^{2}}+\frac{\partial^{2} T}{\partial z^{2}}=\frac{1}{\alpha} \frac{\partial T}{\partial t} \quad \text { at } \quad r=0
$$

\section{Initial conditions}

The temperature of the metal at $t=0$ equal $T_{a m b}$.

\section{Boundary conditions:}

The boundary conditions at both sides, bottom and top for cylindrical sheet surfaces subjected to convection with heat transfer coefficient $h$ into the ambient at temperature $T_{a m b}$ (except the top surface under the laser spot area there is a heat flux boundary condition $q)$.

The incident laser beam has a Gaussian transverse intensity distribution. The incident intensity $I_{\text {inc }}$ is

$$
\begin{aligned}
I_{\text {inc }} & =I_{0} \exp \left(-2 r^{2} / R_{0}^{2}\right) \quad W / \mathrm{cm}^{2} \\
& =\left(2 P / \pi R_{0}^{2}\right) \exp \left(-2 r^{2} / R_{0}^{2}\right)
\end{aligned}
$$

$\begin{array}{lll}\text { Where } & r & \text { is the radial coordinate. } \\ R_{0} & \text { is the characteristic beam radius. } \\ P & \text { is the beam power }[W] .[7]\end{array}$




\section{CALCULATED RESULTS AND DISCUSSIONS}

Firstly, (I) By using the continuous laser source, as described in the equation (6) and the figure (2) with $20 \mathrm{KW}$ power and spot diameter $(10 \mathrm{~mm})$ to the target as described in the figure (1) with properties listed in the tables $(1)$ and $(2)$, until the first point $(R, Z)=(0,0)$ under laser source at the top surface of target reaches the melting temperature $\left(T_{m}\right)$. By solving the equation(3) taking into account the initial and boundary conditions as described above by using the MATLAB environment.

For laser-metal interaction the most important optical properties of the metal is its reflectivity $(R)$, taking equal to $90 \%$ for $N d: Y A G$ laser having $\lambda=1.06 \mu \mathrm{m}$.

Then the absorbed intensity by the metal is then

$$
I_{\text {absorb }}=I_{\text {inc }}(1-R) \quad W / \mathrm{cm}^{2}
$$

Figures(3),(6) and (9) show that the temperature at the surface reaches the melting point after $(460 \mathrm{~m} \mathrm{sec}),(30 \mathrm{~m} \mathrm{sec})$ and $(46.25 \mathrm{~m} \mathrm{sec})$ for aluminum, magnesium and titanium respectively. The heat growth at the surface for aluminum, magnesium and titanium are found to have an average rate of $1.435 * 10^{3} \mathrm{C}^{\circ} / \mathrm{sec}, \quad 21.66^{*} 10^{3} \mathrm{C} / \mathrm{sec}$ and $36.11 * 10^{3} \mathrm{C} / \mathrm{sec}$ respectively.

From previous, (i) We fined that titanium is faster than magnesium and aluminum due to low thermal diffusivity or low thermal conductivity of titanium, for example at a depth of $2.5 \mathrm{~mm}$ the temperature reaches $37.47 \mathrm{C}^{\circ}, 33.56 \mathrm{C}^{\circ}$ and $20.06 \mathrm{C}^{\circ}$ after $15 \mathrm{~m} \mathrm{sec}$ for aluminum, magnesium and titanium respectively.

(ii) For metals with high conductivity the temperature penetrates along the depth, for metals with low conductivity the temperature is accumulated near the surface.

Figures $(4),(7)$ and (10) show the dependence of the temperature contours on the depth and the radius in aluminum, magnesium and titanium respectively.

Figures (5),(8) and(11) show the variation of the temperature with time at $\mathrm{R}=0$ and $\mathrm{Z}$ as a parameter calculated in aluminum, magnesium and titanium respectively.

(II) By using the pulsed laser source, as described in the equation (6) and the figure (12) with $25 \mathrm{KW}$ power, spot diameter $(10 \mathrm{~mm})$ and pulse duration $\tau=25 \mathrm{~m} \mathrm{sec}$ to the previous target with the same all conditions described above in $(I)$.

Figure(13) shows the dependence of the temperature contours on the radius and the depth calculated in aluminum, the position of points $A, B$ and $C$.

Figure (14) shows that the temperature at the surface(point A) reaches the melting point after $(630 \mathrm{~m} \mathrm{sec})$ and the temperature variants with the change of pulsed power source from high to low.

Secondly, as the first point reaches its melting temperature, the melting starts at the surface, there is now a liquid layer over the solid and a moving interface between liquid and solid, the processes of heating and melting are now analyzed using the energy balance equations of all nodes. Solving by Newton Raphson method, in both liquid and solid region. At the beginning of the process, the heat energy induced by laser radiation converted to the latent heat of melting in the sample. As the process continues the interface between liquid and solid moves and the heat is conducted through the liquid metal. By using the continuous laser source, as described in the equation (6) and the figure (2) with $15 \mathrm{KW}$ power and spot diameter 
$(5 \mathrm{~mm})$ to the previous target with the same all conditions described above in $(I)$.

Figure (15) shows the temperature contours as a function of the radius and the depth in both melt and solid, calculated in aluminum, at first step $\left(t_{1}=2.3 m \mathrm{sec}\right),\left(d z_{1}=0.028 \mathrm{~mm}\right)$.

Figure(16) shows the temperature contours as a function of the radius and the depth in both melt and solid, calculated in aluminum, at second step $\left(t_{2}=12.1 \mathrm{~m} \mathrm{sec}\right)$, $d z_{2}=0.167 \mathrm{~mm}$.

Table 1 . The thermodynamic properties of used materials [8]

\begin{tabular}{|c|c|c|c|c||}
\hline Material & $\begin{array}{c}\text { Melting } \\
\text { point } C^{\circ}\end{array}$ & $\begin{array}{c}\text { Melting } \\
\text { Heat } \mathrm{Jg}^{-1}\end{array}$ & $\begin{array}{c}\text { Boiling } \\
\text { Point } C^{\circ}\end{array}$ & $\begin{array}{c}\text { Evaporation } \\
\text { Heat } \mathrm{Jg}^{-1}\end{array}$ \\
\hline \hline Aluminum & 660 & 1,060 & 2,500 & 12,000 \\
\hline Magnesium & 650 & 1,090 & 1,095 & 6,000 \\
\hline Titanium & 1,670 & 1,500 & 3,300 & 10,000 \\
\hline
\end{tabular}

Table 2. The Physical properties of used materials [8]

\begin{tabular}{|c|c|l|l|c|}
\hline Material & $\begin{array}{c}\text { Density, } \\
\rho \\
g \mathrm{~cm}^{-3}\end{array}$ & $\begin{array}{l}\text { Heat capacity, } \\
c_{p} \\
\mathrm{Jg}^{-1} \mathrm{~K}^{-1}\end{array}$ & $\begin{array}{l}\text { Thermal con- } \\
\text { ductivity } k, \\
\mathrm{~J} \mathrm{~cm}^{-1} \mathrm{~s}^{-1} \mathrm{~K}^{-1}\end{array}$ & $\begin{array}{c}\text { Thermal dif- } \\
\text { fusivity, } \alpha \\
\mathrm{cm}^{2} \mathrm{~s}^{-1}\end{array}$ \\
\hline \hline Aluminum & 2.7 & 0.9 & 2.0 & 0.83 \\
\hline Magnesium & 1.74 & 1.0 & 1.0 & 0.57 \\
\hline Titanium & 4.5 & 0.5 & 0.2 & 0.086 \\
\hline
\end{tabular}




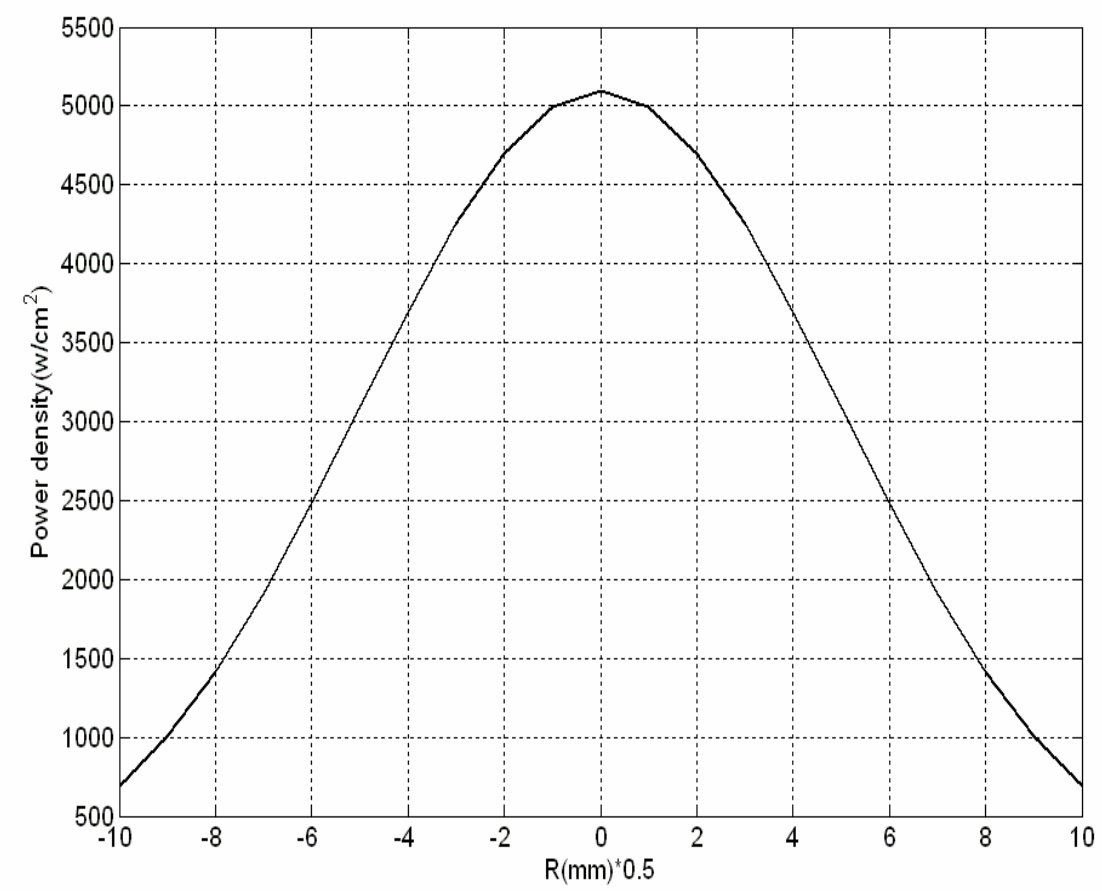

Fig.2. the radial dependence of the Gaussian distributed laser intensity.

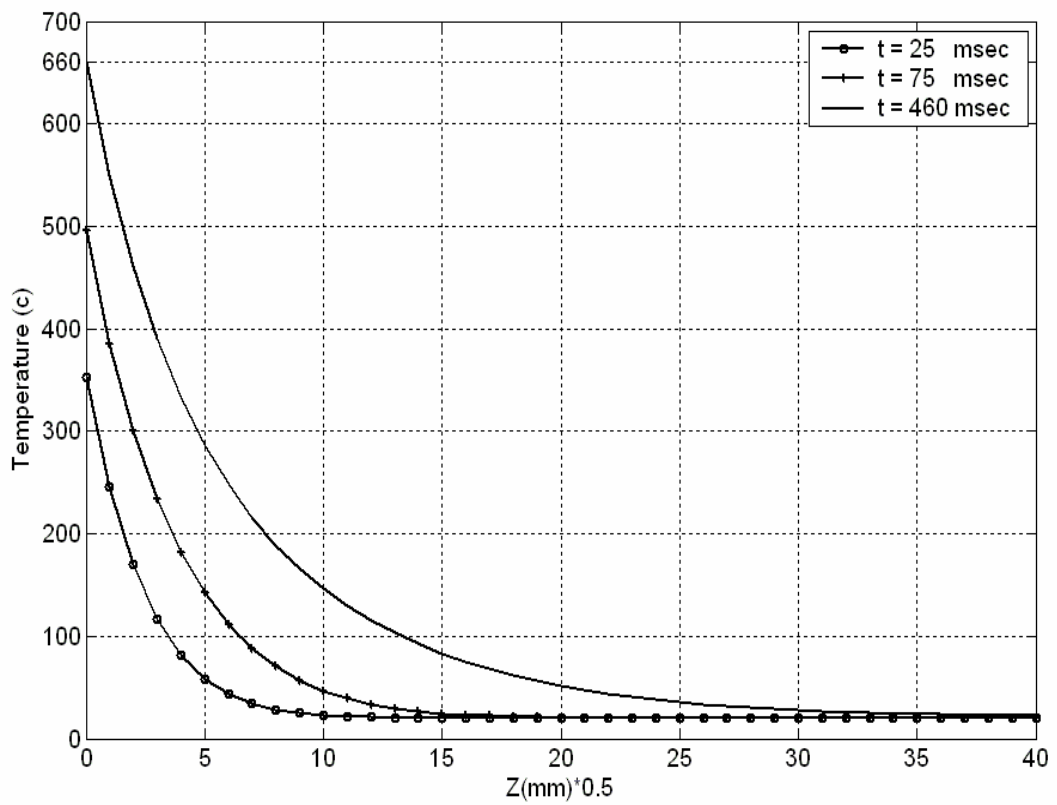

Fig.3. the variation of the temperature along the depth at $\mathrm{R}=0$ and the time as a parameter calculated in aluminum. 


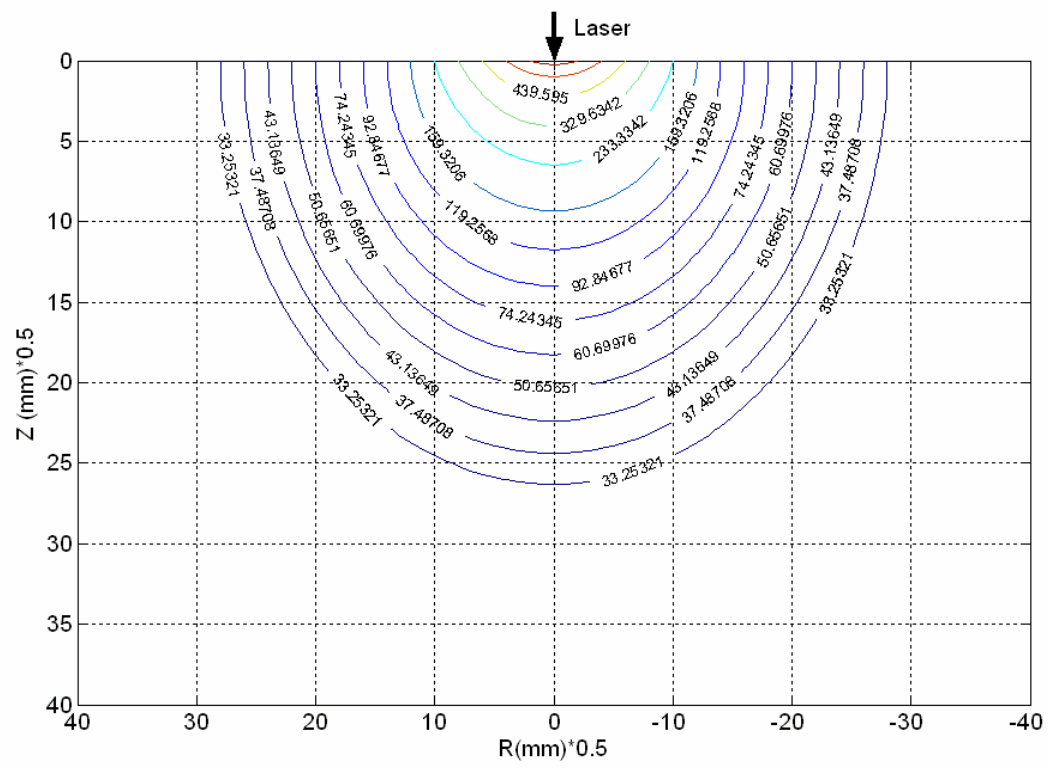

Fig.4. the dependence of the temperature contours on the depth and the radius in aluminum.

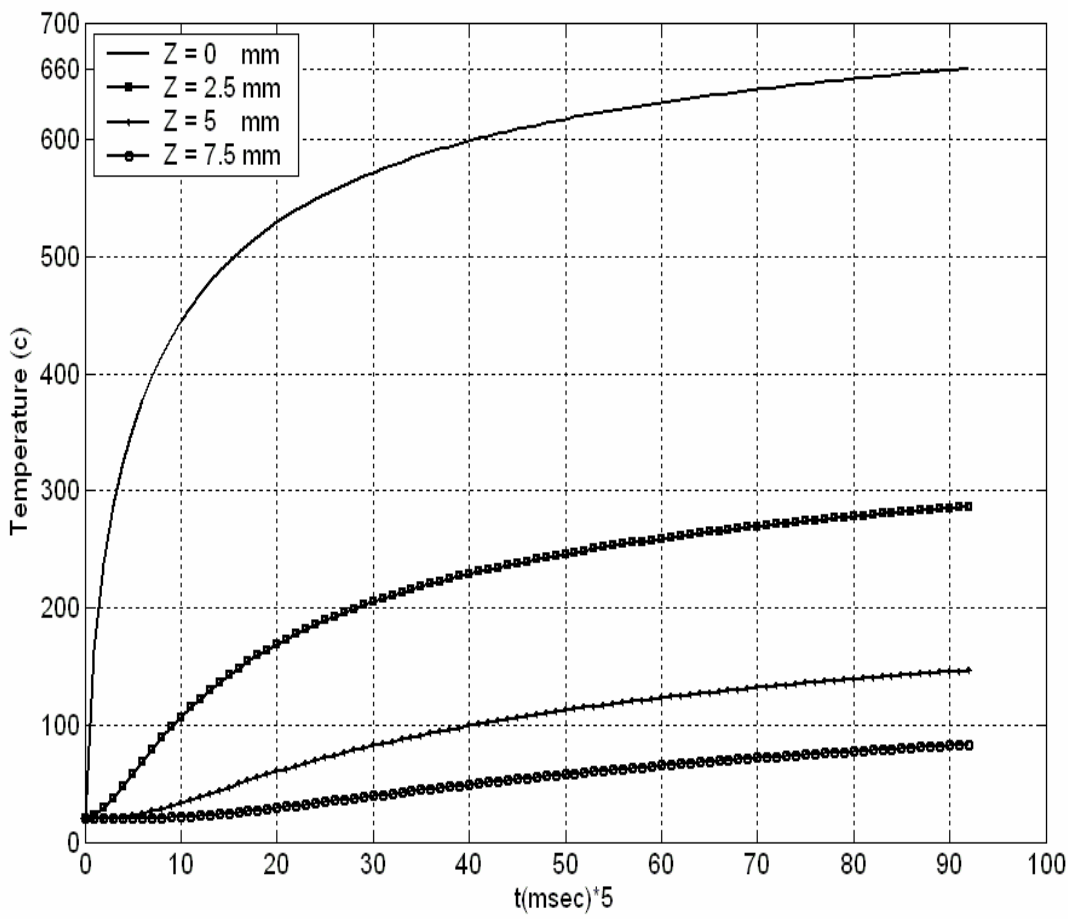

Fig.5. the variation of the temperature with time at $\mathrm{R}=0$ and $\mathrm{Z}$ as a parameter calculated in aluminum. 


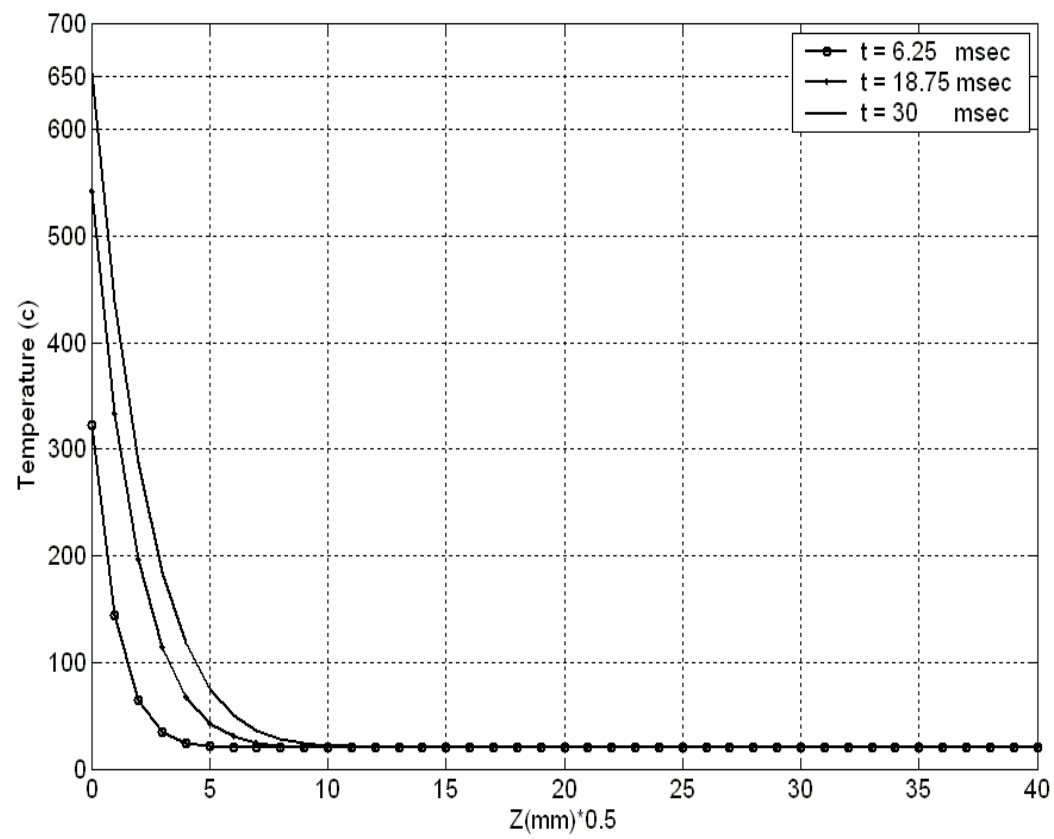

Fig.6. the variation of the temperature along the depth at $\mathrm{R}=0$ and time as a parameter calculated in magnesium.

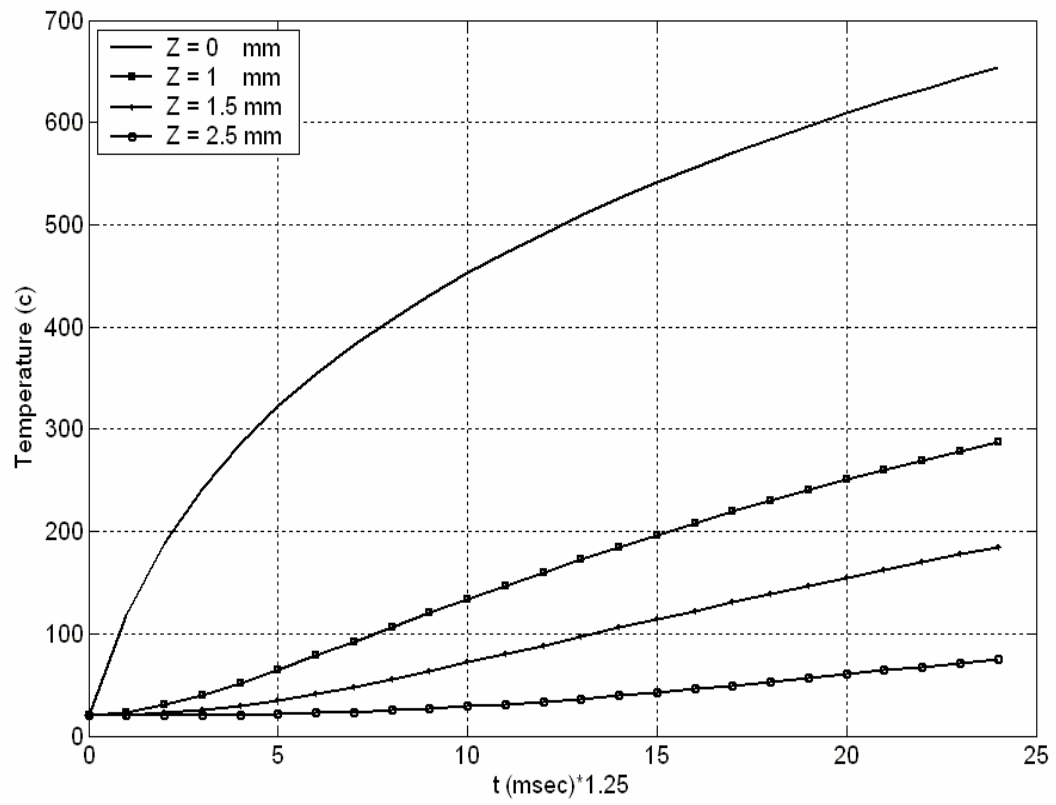

Fig.7. the dependence of the temperature contours on the depth and the radius in magnesium. 


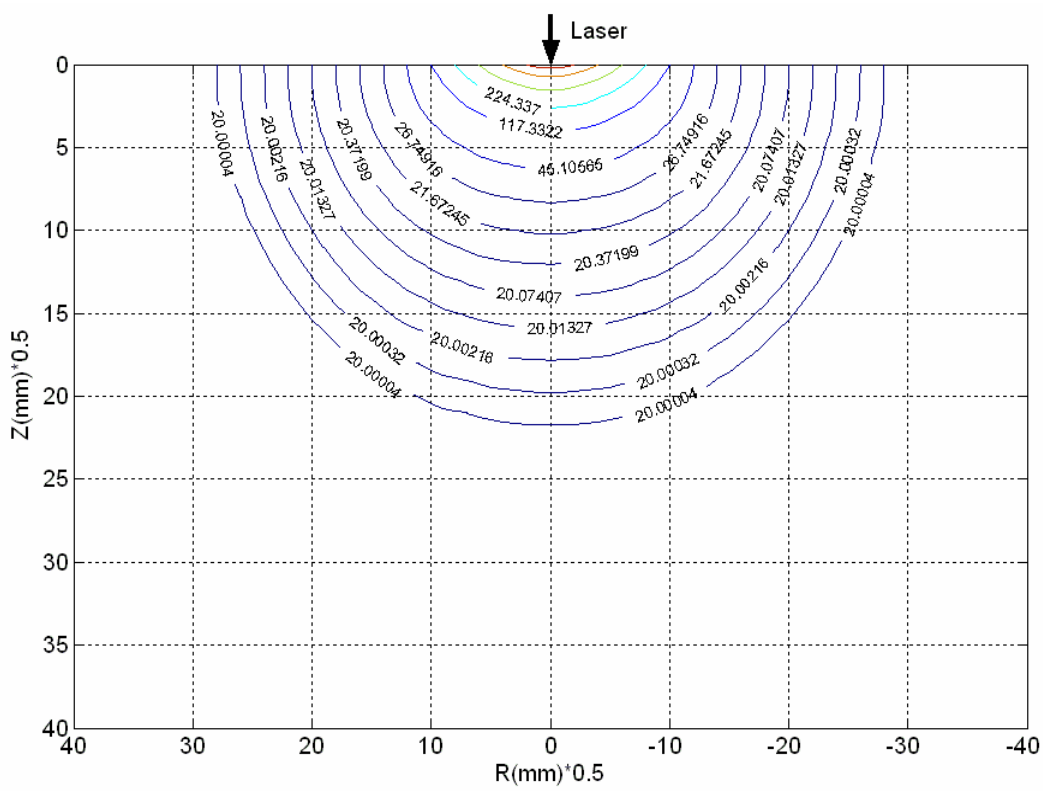

Fig.8. the variation of the temperature with time at $\mathrm{R}=0$ with $\mathrm{Z}$ as a parameter calculated in magnesium.

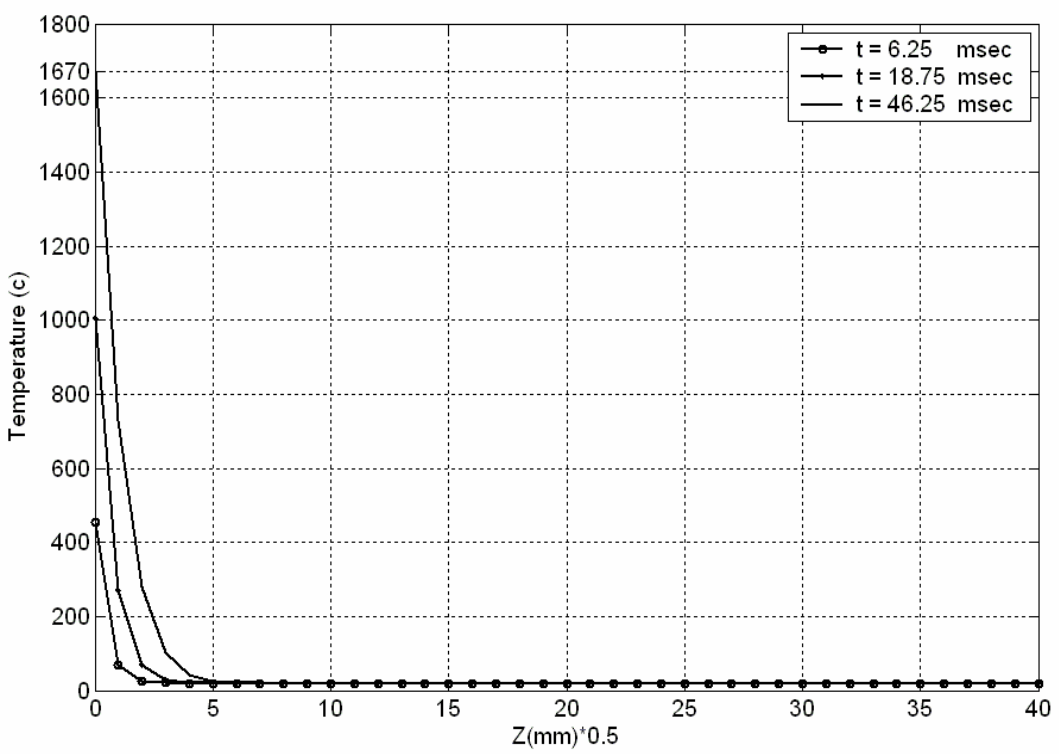

Fig.9. the variation of the temperature along the depth at $\mathrm{R}=0$ with time as a parameter calculated in titanium. 


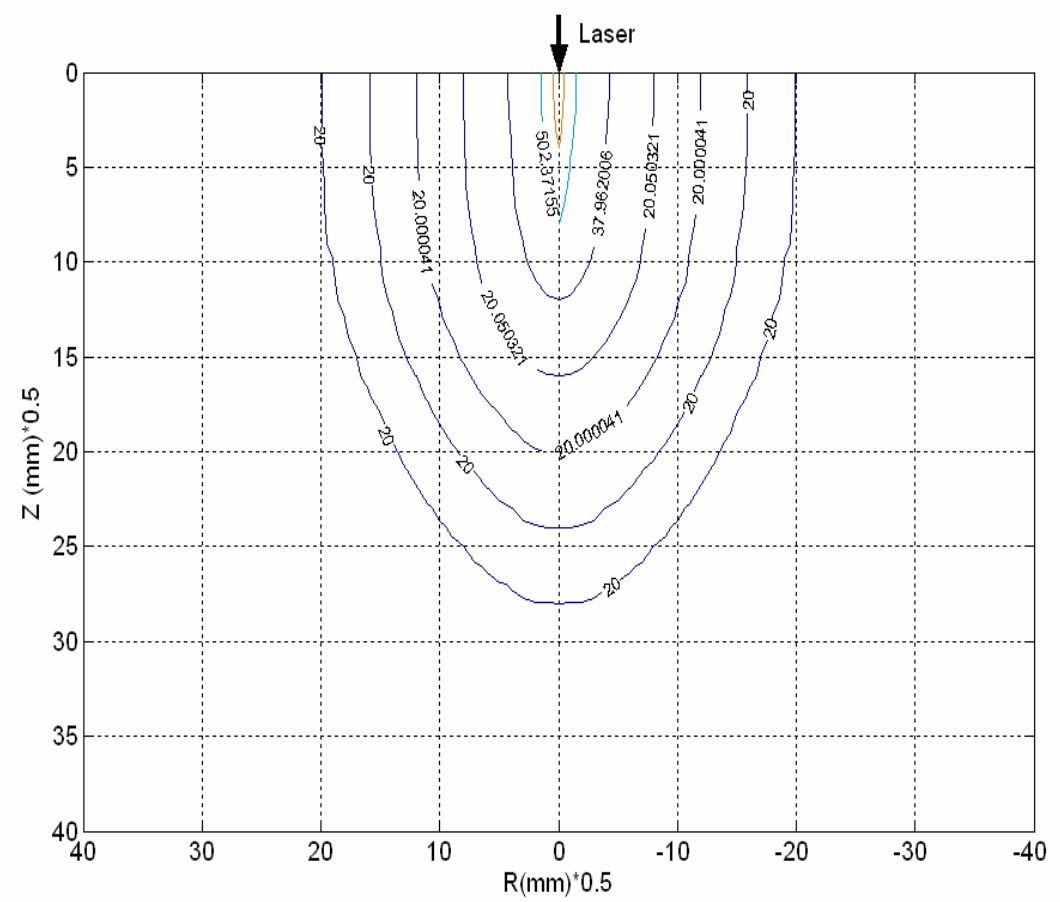

Fig. 10. the dependence of the temperature contours on the depth and the radius in titanium.

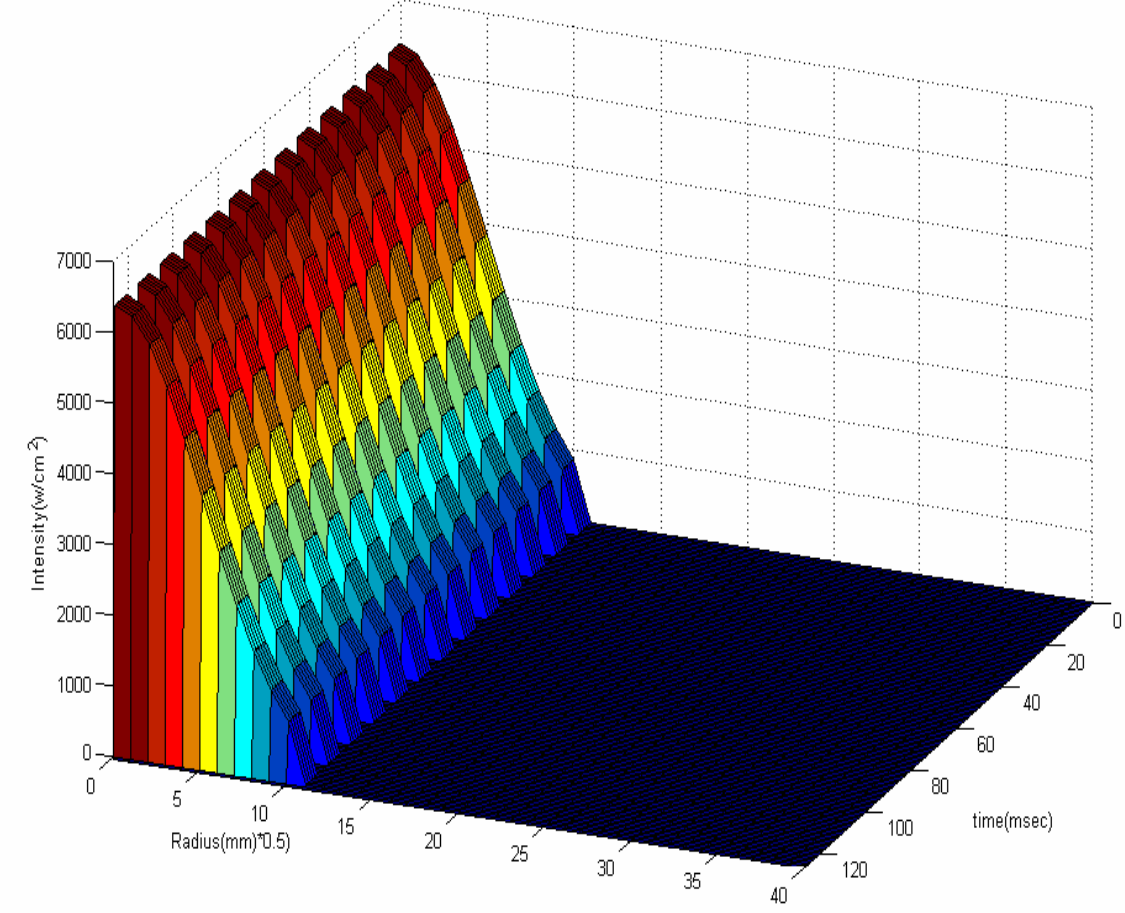

Fig.11. the variation of the temperature with time at $\mathrm{R}=0$ and $\mathrm{Z}$ as a parameter calculated in titanium. 


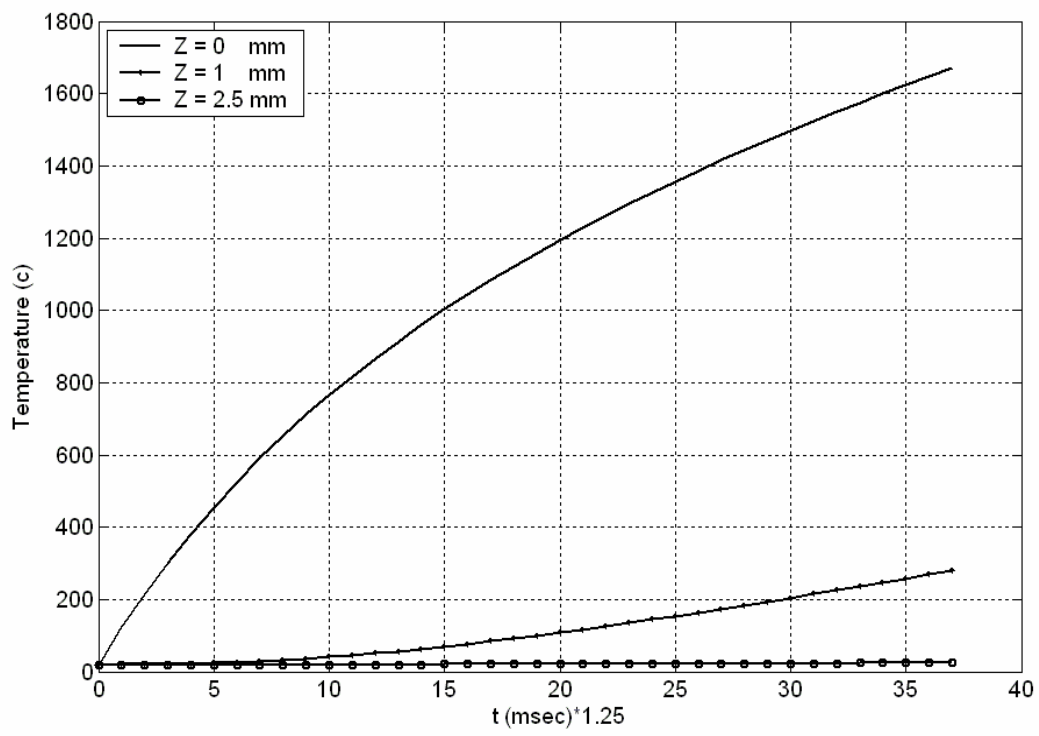

Fig.12. the variation of the pulsed power density with both radius and time.

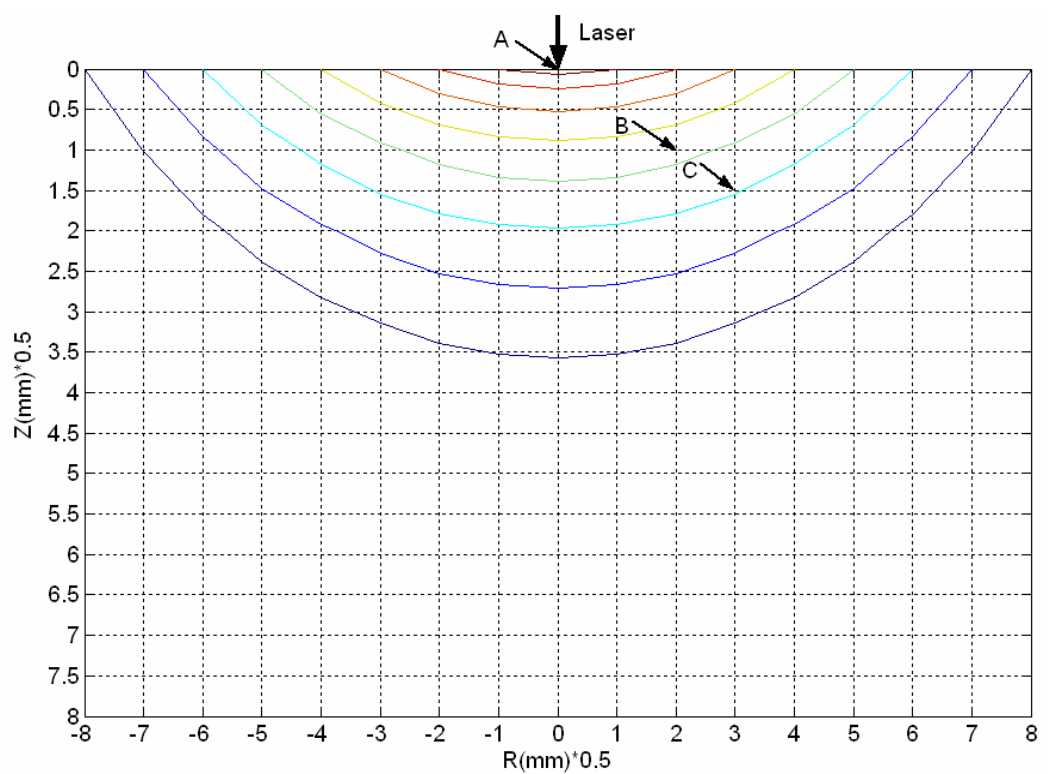

Fig.13. the dependence of the temperature contours on the radius and the depth, calculated in aluminum, the position of points $A \& B \& C$. 


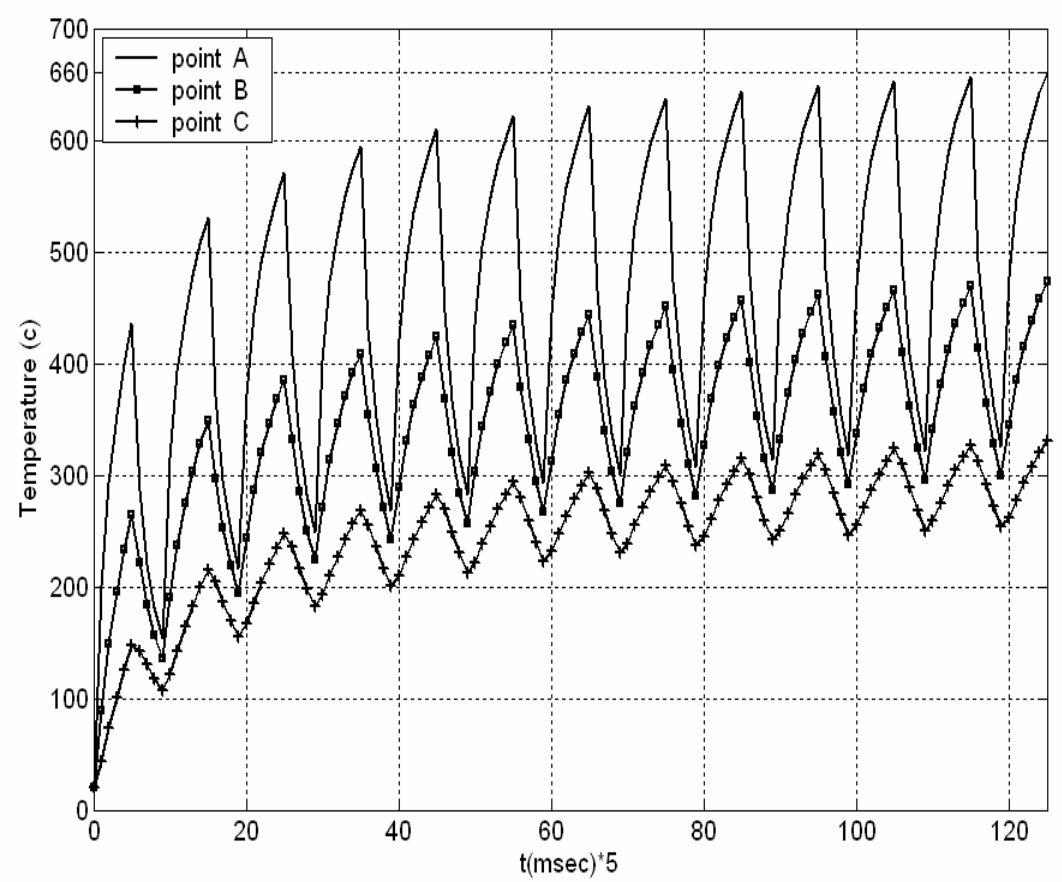

Fig.14. the variation of the temperature with time calculated in aluminum at points $A \& B \& C$

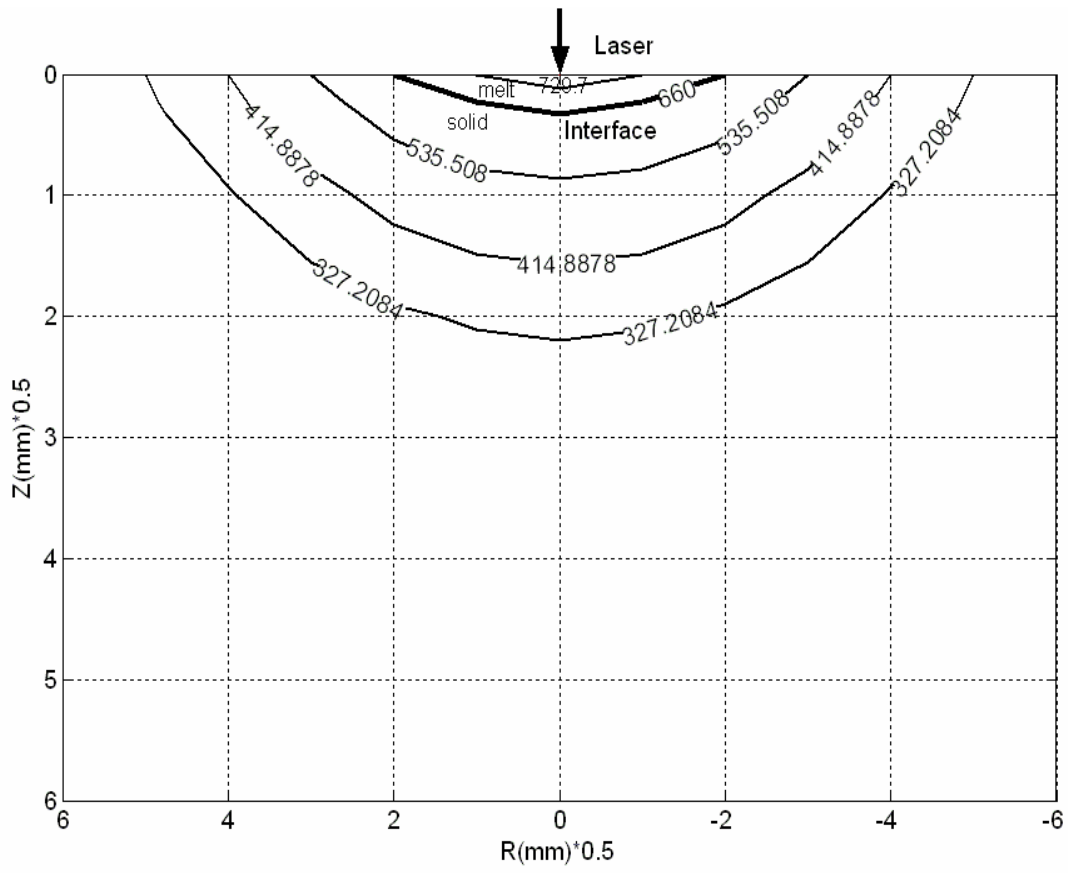

Fig.15. the temperature contours as a function of the radius and the depth calculated in aluminum, at first step $\left(t_{1}=2.3 \mathrm{~m} \mathrm{sec}\right)$

,$\left(d z_{1}=0.028 \mathrm{~mm}\right)$. 


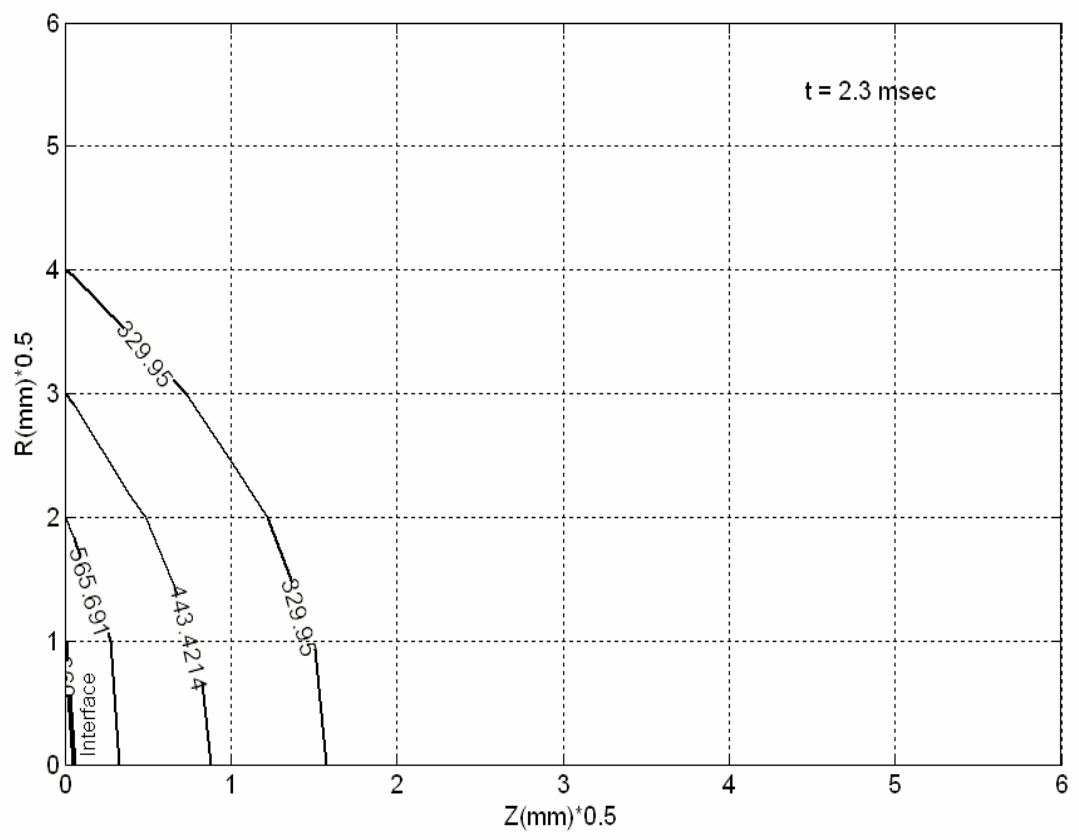

Fig.16. the temperature contours as a function of the radius and the depth in aluminum, at second step $\left(t_{2}=12.1 \mathrm{~m} \mathrm{sec}\right), d z_{2}=0.167 \mathrm{~mm}$.

\section{CONCLUSIONS}

In this work, we present a two-dimensional calculation of the interaction of a laser beam with metallic targets, a single and a double phase cylindrical axisymetrical models are established by using finite difference method, the Newton Raphson method to solve the energy balance equations of all nodes in both liquid and solid regions.

The single phase model described the heating of metal before melting take place, while the double phase model described the occurrence of melting of metals, calculation runs for different target metals such as aluminum, magnesium and titanium.

The calculation leads to:

1-A two-dimensional variation of temperature distribution of the target against depth at certain time intervals.

2-The temperature fields in both melt and solid regions and the moving boundary positions at different times.

3-For metals that have low diffusivity, the temperature distribution along depth nearly that as for one-dimension.

4-The moving boundary problem is a common problem in the nature, specially the process of laser melting. The application of the model calculation that, provides a way to understand the physical process of a laser-metal interaction.

\section{References:}

[1] John F. Ready“ Industrial Applications of Lasers” 1978.

[2] Adrian Bejan, “Heat Transfer”, edited by John Wiley \& Sons, Duke University Inc. 1993. 
[3] J. P. Holman“ Heat Transfer" edited by McGraw-Hill, Inc Eighth Edition, Southern Methodist University, 1997.

[4] Frank P. Incropera, David P. Dewitt“Introduction to Heat Transfer" third edition, edited by Johan wiley, sonc. Purdue University, 1996.

[5] M.Necati Özisik“ Finite Difference Methods in Heat Transfer" edited by CRC press Boca Raton Ann Arbor, North Carolina State University. 1994.

[6] J.Alan Adams,David.F.Rogers"'Computer-Aided Heat Transfer Analysis", Mcgraw,Hill.Inc,1973.

[7] Armon, E., Y. Zvirin, G. Laufer, and A. Solan, 1989a, "Metal Drilling with a CO2 Laserbeam. I. theory", J. Appl. Phys., 65(12):4995-5002.

[8] Andrei Kokoshin“" Weaponry in Space the Dilemma of Security” edited by Yevgeni Velikhov, U.S.S.R Academy of Sciences 1986. 